\title{
Comparison study on evaluating urban traffic, transport system and services in China and Japan
}

\author{
R. Ando \& M. Kawai \\ Research Department, Toyota Transportation Research Institute, Japan
}

\begin{abstract}
Over recent years, cities have been growing rapidly and motorization is expanding at a very quick pace in China. As a result, many problems relevant to traffic, transport systems and services have occurred in urban areas. In view of this situation and the social conditions, the central government has set forth a system called Action Program for Smooth Traffic and Transport. All cities/provinces/autonomous regions have been requested to apply this action program to improve the cities by evaluating progress of the situation. Before the problem deteriorates further, all Chinese cities have been acting positively in tackling the problems of urban traffic and transport by utilizing this program since its start in 2000 . One characteristic of this action program is that 75 indicators including all respects of the urban traffic, the transport system and services have been used for evaluating and ranking the cities. Another characteristic is that the indicators changed year by year from 59 indicators proposed in 2000. In this paper, we try to clarify the feature of the indicators used in the evaluation system of urban traffic and transport after summarizing the Action Program for Smooth Traffic and Transport. Through the analysis, we will make it clear what stage the urban traffic and transport system are at, how the Action Program for Smooth Traffic and Transport is functioning for the change of the urban traffic and transport system and finally, what are the effects the evaluation system to the improvement the traffic and transport environment. To compare with Japan, a local version of the Performance Plan and Achievement Degree Report in Japan is also taken into consideration.

Keywords: Smooth Traffic and Transport, Action Program, evaluating indicator, China, Japan.
\end{abstract}




\section{Introduction}

In recent years, in the People's Republic of China, where city growth is remarkable, many problems relevant to traffic and transport have occurred in urban areas as the motorization progresses too quickly. To control the situation, the central government created the Action Program for Smooth Traffic and Transport and informed all cities under the municipalities, provinces and autonomous regions. Action Program for Smooth Traffic and Transport is an evaluating system with a systematic indicators table. Points by each indicator are evaluated respective with the current progress situation for all objective cities and then a grade according to the points can be evaluated. Facing the reality of aggravation of the traffic situation in each city, most of the cities in China have acted positively to this measure since 2000 when it was first introduced.

On the other hand, in Japan, at the background of the people's high concern about all public works including road improvement, the evaluating system to check the needs and to make the analysis about the cost effectiveness before starting, during the implementation and after the operation starting, has been introduced and carried out. The evaluation is performed by the outcome indicators that can show people how the profits are obtained according to the public works in Japan. Here, there is a big change in that the indicators have been changed to be the outcome type from the output type indicators used before to improve the accountability to the people. Furthermore, the Performance Plan and Achievement Degree Report had been introduced to manage the progress of the public works and are drawn up by the national highway office cooperated with the prefecture and cities/towns/villages for a given fiscal year. This system was started in 2003 and the first target year is 2007 . The achievement degrees in 2007 and in each fiscal year before 2007 are set forth based on the situation and figures in 2002. The Performance Plan and Achievement Degree Report works at all levels, the whole country and the regional level.

It is thought that the evaluation system of the public works relating with the traffic and transport in two countries is greatly different from the development process of each country, the difference in the people's viewpoints and the difference in the political organization etc.

In this paper, the measure situation for each city and the features of the Action Program for Smooth Traffic and Transport are to be discussed as an evaluating system in China. Furthermore, the measures in terms of Performance Plan and Achievement Degree Report for all prefectures in Japan are summarized and then the issues are discussed. By comparing two systems, the points which can be referred to by each other are to be summarized.

\section{Action Program for Smooth Traffic and Transport in China}

\subsection{Outline of Action Program for Smooth Traffic and Transport}

Action Program for Smooth Traffic and Transport (Project for Smooth Flow is a direct translation or "Chang-tong Gong-cheng" in Chinese) was introduced in 
2000 in China. An evaluation system and a group of indicators for urban road traffic and transport management are given by the Traffic Management Administration Bureau of the Ministry of Public Security, and the Urban Development Bureau of the Ministry of Housing and Urban-Rural Development. All cities conduct the evaluations by following this system and using the indicators listed in it. After the self-evaluation made by each city, the central government and the provincial governments summarized the results checked by the expert group and then evaluated as the first to fourth grade. Finally, they announced the result to the public.

Action Program for Smooth Traffic and Transport has been released many times since 2000. The editions of 2000, 2002, 2003, 2004 and 2005 have been obtained through the website and an interview investigation we made in 2007. In this study, the 2005 edition is the target. Here, when we see the change of indicators number, as Table 1 shows, the number of indicators has changed from 59 in the 2000 edition to 75 in the 2005 edition. The evaluation indicators have been revised every year related on the classification of basic and additional indicators, the contents and the approaches. Especially, in the 2005 edition where the evaluation indicators relevant to the bus transport system were added.

Table 1: $\quad$ No. of indicators by year*.

\begin{tabular}{|c|c|c|c|c|c|c|}
\hline Year & 2000 & 2001 & 2002 & 2003 & 2004 & 2005 \\
\hline No. of indicators & 59 & 56 & 65 & 64 & 69 & 75 \\
\hline
\end{tabular}

*Two indicators are divided by either daytime or nighttime during 2003-05.

\subsection{Classification of evaluation criteria}

Again, as stated above, Action Program for Smooth Traffic and Transport consists of the basic evaluation indicators (55 in the 2005 edition) being applied for all cities and the additional evaluation indicators (20 in the 2005 edition) being applied for the specified cities according to the classification of cities. In Action Program for Smooth Traffic and Transport, the cities are classified as 5 groups. The "special cities" mean Beijing and Shanghai. The "A group" consist of the cities where the GDP in the municipal district is 32 billion RMB Yuan or more, or the population in the municipal district is 2 million or more. The "B group" consists of the cities where the GDP in the municipal district is 16 billion RMB Yuan or more, or 11 billion RMB Yuan or more and the population in the municipal district is 500,000 people or more. The "C group" includes the cities where the GDP in the municipal district is 5,500 million RMB Yuan or more, or the population in the municipal district is 1 million people or more but the GDP is less than 11 billion RMB Yuan. The " $\mathrm{D}$ group" are the remaining cities. Thus, the 75 indicators can be classified by the corresponding cities as shown in Table 2.

Of 20 additional indicators, 15 indicators are for all cities except the D group. Three indicators are for the cities of the special, the A and B groups. One is for the special and the A group cities. One is only for two special cities. 
Table 2: $\quad$ No. of indicators by group of cities in 2005 .

\begin{tabular}{|c|c|c|c|c|c|}
\hline & Basic & \multicolumn{4}{|c|}{ Additional } \\
\hline & All cities & $\begin{array}{c}\text { Special } \\
+\mathrm{ABC}\end{array}$ & $\begin{array}{c}\text { Special } \\
+\mathrm{AB}\end{array}$ & $\begin{array}{c}\text { Special } \\
+\mathrm{A}\end{array}$ & Special \\
\hline $\begin{array}{c}\text { No. of } \\
\text { indicators }\end{array}$ & 55 & 15 & 3 & 1 & 1 \\
\hline
\end{tabular}

By any one of the indicators, the evaluated cities are evaluated into five grades. The standard to evaluate the cities for every indicator may be different to consider the difference of the classification of city. As an example, the standard of the indicator No. 7, the share of public transport, is shown in Table 3. There are three standards divided by the city group. This means, for example, when the share of the public transport is $13 \%$, the city is evaluated as Grade 4 if it belongs to the A group and Grade 2 if the city is the $\mathrm{C}$ group. Thus, this indicator shows people a direction the large scale cities should improve the share of the public transport in the city higher and higher.

Table 3: Indicator of the share of public transport.

\begin{tabular}{|c|c|c|c|c|c|c|}
\hline \multicolumn{2}{|c|}{ Evaluation level } & 1 & 2 & 3 & 4 & 5 \\
\hline \multirow{2}{*}{$\begin{array}{c}\text { Standard by } \\
\text { the city group } \\
(\%)\end{array}$} & $\begin{array}{c}\text { Special and A } \\
\text { group }\end{array}$ & $\geq 22$ & $18-22$ & $14-18$ & $10-14$ & $<10$ \\
\cline { 2 - 7 } & B group & $\geq 19$ & $15-19$ & $11-15$ & $7-11$ & $<7$ \\
\cline { 2 - 7 } & C group & $\geq 15$ & $12-15$ & $9-12$ & $6-9$ & $<6$ \\
\hline \multicolumn{2}{|r|}{ Evaluating point } & $90-100$ & $80-90$ & $70-80$ & $60-70$ & $<60$ \\
\hline
\end{tabular}

On the other hand, 37 indicators (67\%) among 55 basic indicators are based on the only one standard without consideration of the classification of the city scale. However, regarding the additional indicators, 11 indicators, that is more than $50 \%$ of all 20 additional indicators, are applying by two or more classifications of the standard. That is, there is a thought that simply do by the basic indicators and describe in detail by the addition indicators.

\subsection{Contents and approaches of evaluation criteria}

The evaluation indicators are classified into 10 criteria as shown in Table 4. All evaluation indicators regarding the traffic safety are the basic indicators including the topic of the safety education, the traffic ordering such as the number of illegal parking vehicles, and the traffic accident such as the number of accidents and the fatalities. Furthermore, the indicators relative with both road and traffic facilities improvement are defined as the basic indicators, too. On the other hand, nine of 12 indicators in the classification of the land use and public transport are treated as the additional indicators. The indicators about the bus operation are added in 2005 as the necessity for the public transport promotion had become more important recently in the urban areas, but most of them are the additional indicators. 
The evaluation by each indicator is carried out qualitatively or quantitatively. As summarized in Table 4, 13\% of all basic indicators and 25\% of all additional indicators are qualitative evaluation. Among quantitative indicators, $60 \%$ of the basic indicators and $62 \%$ of the additional indicators are evaluated by ratios (or percentages). The representative qualitative indicators are based on the criteria "Management system, Policy and plan", "Land use and public transport", "Traffic control facility", "Measure of traffic management", and "Modernization of road management". Regarding the "Management system, Policy and plan", for example, there is an indicator named "traffic management planning". Whether the present condition of urban transport is analyzed based on the traffic surveys or the investigation of public transport, and whether the planning has been discussed to solve the problems is evaluated. Similarly, the participation of experts or specialists, and the release to the mass media, makes the evaluation going up.

Table 4: $\quad$ Classifying of indicators.

\begin{tabular}{|c|c|c|c|c|c|c|}
\hline & \multicolumn{3}{|c|}{ Basic } & \multicolumn{3}{|c|}{ Additional } \\
\hline & \multirow{2}{*}{$\begin{array}{l}\text { Quali- } \\
\text { tative }\end{array}$} & \multicolumn{2}{|c|}{ Quantitative } & \multirow{2}{*}{$\begin{array}{l}\text { Quali- } \\
\text { tative }\end{array}$} & \multicolumn{2}{|c|}{ Quantitative } \\
\hline & & ratio & others & & ratio & others \\
\hline $\begin{array}{l}\text { 1. Management system, } \\
\text { Policy and plan }\end{array}$ & 2 & & & 2 & & \\
\hline $\begin{array}{l}\text { 2. Land use and public } \\
\text { transport }\end{array}$ & & 2 & 1 & 2 & 4 & 3 \\
\hline 3. Road facility & & 6 & 3 & & 1 & \\
\hline $\begin{array}{l}\text { 4. Traffic control } \\
\text { facility }\end{array}$ & 1 & 6 & 3 & & 2 & \\
\hline $\begin{array}{l}\text { 5. Measure of traffic } \\
\text { management }\end{array}$ & 2 & 5 & 2 & 1 & 1 & \\
\hline $\begin{array}{l}\text { 6. Education of traffic } \\
\text { safety }\end{array}$ & & 4 & & & & \\
\hline $\begin{array}{l}\text { 7. Modernization of } \\
\text { road management }\end{array}$ & 2 & & & & 3 & \\
\hline 8. Order of traffic & & 5 & 1 & & & \\
\hline 9. Transport operation & & & 2 & & 1 & \\
\hline 10. Traffic safety & & 6 & 2 & & & \\
\hline Total & 7 & 34 & 14 & 5 & 12 & 3 \\
\hline Percentages & $13 \%$ & $62 \%$ & $25 \%$ & $25 \%$ & $60 \%$ & $15 \%$ \\
\hline
\end{tabular}

\subsection{An analysis in terms of the evaluation result}

As shown in Table 5, the objective cities increased from 706 in 2003 to 837 in 2005. Furthermore 13 cities in 2003 were evaluated as the first grade (sharing $1.8 \%$ of all objective cities), but the number of the first grade became 23 cities (sharing 2.7\%) in 2005. Moreover, same thing can be seen with the second grade. 91 cities (12.9\%) in 2003 increased to be 218 cities (26.0\%) in 2005. That 
means not only the number of cities with higher glades but also the percentages over all objective cities increased. The system made the cities improve actively and that brought a positive situation.

Table 5: $\quad$ No. of cities by grade* from 2003 to 2005.

\begin{tabular}{|r|r|r|r|r|r|r|}
\hline & \multicolumn{1}{|c|}{ First } & \multicolumn{1}{c|}{ Second } & \multicolumn{1}{l|}{ Third } & \multicolumn{1}{l|}{ Fourth } & \multicolumn{1}{c|}{ Out } & \multicolumn{1}{c|}{ Total } \\
\hline 2003 & 13 & 91 & 362 & 217 & 23 & 706 \\
\hline 2004 & 16 & 171 & 313 & 254 & 13 & 767 \\
\hline 2005 & 23 & 218 & 376 & 219 & 1 & 837 \\
\hline
\end{tabular}

*Including all cities evaluated by either the central government or the province.

The system allows for all cities, where the related people have done their best to improve the current situation, to move their grades up. For example, in Shandong Province where we visited and made the interviews, there were no cities that lowered their grades over the past years because they have improved the road construction situation year by year so that the related indicators had gone up. This implies that the system show the administration staff to do what they should do.

\subsection{Feature of Action Program for Smooth Traffic and Transport}

The feature of Action Program for Smooth Traffic and Transport in China can be summarized as the followings in terms of the above and our analysis.

-A uniform system over the whole country. The notification from the central government guarantees the evaluation standard.

-The application can be case by case according to the city scale.

-The quantitative indicators are used abundantly.

-The qualitative indicators are also united and compounded to let the system work well.

-The central government specifies the direction what they are considering by the qualitative indicators.

-A mechanism to higher the motivation of the people working in the cities is designed and included in the system. That is, it is clear that the people should work hard to let the grade be up through the evaluation under the system.

-The indicators which suited for the developing countries' actual conditions is introduced.

-The evaluation process is also suited for the developing countries. That is, the evaluation is possible even if not all indicators are in hand.

-The evaluation is an absolute by the indicators and is relative by the grading, too.

-The continuous improvement of the system itself has been carried out. For example, the number of indicators has been changed every year.

-The improvement level for every city can be raised as the grade of the evaluation is going up. This demonstrates the effect to the public timely. 


\subsection{Short comments on the Chinese system}

In China, the local governments such as provinces or cities are considered as playing the role of the central government like the branches. However, all local governments are sometimes requested to secure their budgets by themselves. In the cities with one or more special development areas etc., the GDP in the cities increases and the tax revenues also increase. As a result, the investment to the infrastructure improvement is performed positively. This brings the city being evaluated with a higher grade in terms of Action Program for Smooth Traffic and Transport. Thus, Action Program for Smooth Traffic and Transport is thought that it is the evaluating system with the effective indicators being able to contribute to make the whole improvement and maintenance level going up. The evaluation by such a system with a clear grade can let the organization to make their goal clearly, and furthermore help the staff in charge to keep their motivation. An example was taught when we made an interview in Yantai City locating in Shandong Province. Weihai City, a city adjoining to Yantai, was evaluated as the first grade, but Yantai was the second grade. This fact brought the personnel of Yantai City to be competitive. To obtain the higher evaluation, they performed much more actively so that many measures are carried out very effectively.

On the other hand, as all indicators have the limited points, all cities have to deal with all respects in order to approach the higher evaluation. The result is that the cities find it difficult to conduct their special and original measures even if it may fit for the city's best. This kind of system is effective for the cities in the primary stage but may bring many problems or new issues such as no originality for the cities after the primary stage.

Moreover, we think the evaluation results should be opened to the public by the categories of the cities scales, so that the cities being small scale and evaluated with a lower grade may have a clearer goal best fit to themselves.

\section{Evaluation system for the public works on road traffic and transport in Japan}

In order to clarify the feature of Action Program for Smooth Traffic and Transport, a comparison is made with Japan. As the similar system related with the evaluation for the public works on road traffic and transport, the local edition of Performance Plan/Achievement Degree Report is chosen as it is conducted for the performance evaluation in all local areas.

\subsection{Outline of Performance Plan / Achievement Degree Report}

The Performance Plan/Achievement Degree Report was first released in 2003 by the Road Bureau, the Ministry of Land, Infrastructure and Transport. Since then, performance plans and achievement degree reports have been completed and opened to the public every year. Other than a national version, in order to perform the road administration management at a local level, the local editions 
for all prefectures have been addressed through the Regional Development Bureau etc. However, the contents and process of the implementation are depended on the Regions. Although four regional development bureaus including Tohoku, Kanto, Kyushu and Okinawa has published the target declarations, there are no related reports up to now in Nagasaki Prefecture and Miyazaki Prefecture, both are locating in Kyushu. To see the situation over the entire country, there are still some prefectures where no performance plan/achievement degree report is published even though the total number is increasing.

Furthermore, about the opening to the public, some regions publicised it on the websites of the prefectures and some regions mentioned it on the websites of the national highway offices. The different treatments led to some confusion of the people who confuse the principles and feel difficulty in accessing the documents.

\subsection{Contents of Performance Plan / Achievement Degree Report (the local edition)}

The creation of the performance plan / achievement degree report is requested to refer to Guidance for Road Administration Management (Oct. 2004 Version) published by the Road Bureau, the Ministry of Land, Infrastructure and Transport. In the guidance, 5 policy themes that are traffic safety, traffic congestion release, road construction, management and communication are listed up. Regarding the traffic safety and the traffic congestion, the flowchart to approach a concrete measure is given through a process of extracting parts from many subjects and deciding the priority. On the other hand, regarding the road construction, the management and the communication, to introduce a competitive principle to the road administrative management, the process of feasibility study for the implementation of the work is proposed. In the local edition of the performance plan / achievement degree report, all processes are suggested to be conducted by setting up a target for each prefecture.

Let us take Aichi Prefecture where our institute is located, as an example. In Aichi, before the creation of the performance plan / achievement degree report, Round Table Conference of Road in Aichi was organized attending by the wellknown persons of each field in Aichi. As the output the Conference, six themes were proposed. The first is "road service to support the international exchange district which leads industry in the world". The second is "road service which adds comfort and amenity to the happy lives in the area". The third is "road service supporting a community to be able to prevent a disaster". The fourth is "road service being useful for preservation and improvement of the environment". The fifth is "smooth and safe road service through effective use of the existing road and introduction of hi-technology". The last, that is the sixth, is "road service realizing by participation and cooperation for supporting a harmony and collaborated society". The prior numerical targets in 2003 and 2007 are set up on the basis of the current situation in 2002 in a performance plan. In the achievement degree report of 2003, the first target year, the results 
was shown and compared with the prior target figures, what they had done in the past year.

\subsection{Target and achievements of Performance Plan / Achievement Degree Report (the local edition)}

When we see the present situation conducted in each prefecture, the targets can be divided roughly as the topics of "traffic congestion release", "safe living and traffic safety", "communication", and "additional items". Here the situation investigation is based on the 2006 achievement degree reports and the 2007 performance plans.

Regarding the evaluation indicators on the "traffic congestion release", the indicators can be divided as the indicators evaluated directly by using the traffic congestion data such as the delayed time caused by traffic congestion and average travel speed etc., the indicators to understand what have been done such as number of measures completed, and the indicators with some relation to the traffic congestion release such as decrease of construction time on the road and the percentage making use of expressway. Because each prefecture may set forth its original target, there are many different targets to be evaluated. For example, regarding the interchange of expressway and the service of expressway, many indicators have been applied for, like the number of cities, towns and villages, the population, the area being able to access the interchange in 60 minutes or there is at least one interchange in the central city etc. Regarding the "safe living and traffic safety", the traffic accident rate, the alternative route in case of emergency, the earthquake measure, the rainfall regulation and the prevention of natural disasters etc. are mentioned. Regarding the environment, the indicators related with the influence on the living environment such as sound and air pollution are used. Additionally, the undergrounding of electric wires, the barrier-free and the improvement of road scene are listed too. Furthermore, as the indicators with the "communication", the number to access the website and the number of supporting organizations are applied.

Among the indicators widely used, many are in the expression of outcome instead of the output used before. These outcome indicators are much easier to be understood by the citizens so that the indicators are judged being useful to express the effects of the public works.

All the indicators currently dealing with the achievement degree report / performance plan are quantitative indicators. The target and current situation of achievement can be checked numerically.

Among 38 prefectures we investigated, 35 prefectures make use of the indicators of the delayed time caused by the traffic congestion and the number of casualty accidents (or the rate of casualty accidents). These are the most popular indicators in Japan.

Moreover, for example, the indicators about sightseeing information in the tourist resort region or the indicators targeted to improve the road service during winter in the snow area, the indicators suited for the characteristic of the region have been used as the evaluating indicators. 
To make a summary on the achievement situation over all 38 prefectures, 235 $(58 \%)$ of 403 items set forth as the targets in the performance plans have been successfully approached. 129 items (32\%) have been judged not be successful. There is also 39 items $(10 \%)$ which could not be evaluated.

The indicators with high achievement degree can be listed here. Regarding the targets having been set forth by more than 10 prefectures, that, the "preparation of road for sightseeing" with $80 \%$ (8 in 10 prefectures) and the "noise measures" with $80 \%$ (12 in 15 prefectures) is the representative indicators.

\subsection{Feature of Performance Plan/Achievement Degree Report (the local edition)}

The feature of Performance Plan / Achievement Degree Report in Japan can be summarized as the followings in terms of the above and our analysis.

-Under the principle of the central government, the Regional Development

Bureau of each region takes the leadership and tackle in all prefectures.

-All regions have proposed their original indicators or targets to reflect the

regional characteristics.

-The system is used as the budget related evaluation system.

-Most of the indicators are outcome type and intelligible.

-The system is the management-by-objective type system. The mechanism of

PDCA (Plan-Do-Check-Action) has been introduced so that the targets for the coming year are based on the evaluation result the year before.

-The difference has arisen by the region in the process of deployment.

-There may be a gap between the targets of the regions and the target of the whole country.

-The comparative present conditions cannot be grasped as there are too few common indicators.

\section{Hints to Japanese evaluation system from Chinese Action Program for Smooth Traffic and Transport}

Comparing the Japanese evaluation system of the performance plan / achievement degree report (the local edition) with the Chinese evaluation system of the action program for smooth traffic and transport, the followings points may be considered to be applied for the improvement of the Japanese evaluation system.

\subsection{Responding to the new issues easily}

The indicators are revised every year so that the new indicators responding to the new issues immediately because of the social condition changed or the new policy direction was set forth. In Japan, the every year's updating is limited to renew the figures. Although the different indicators may be used in the different regions, the new indicators are not added. 


\subsection{Enhancing the motivation by the grade evaluation}

On the basis of the interview conducted in Yantai City of China, the evaluation that is made by the outside of the organization can enhance the motivation of the administration organization and the staff working there. If the similar process to open the evaluation results (the achievement degree reports) of all prefectures in a uniform style can be implemented in Japan, the motivation of the related departments and the offices working there may be enhanced similarly.

\subsection{Evaluation of planning by using the qualitative indicators}

In the present performance plan/achievement degree report, all indicators are quantitative. However, at the planning stage of the public works, some achievements may be difficult being evaluated by the quantitative indicators only. Not only the quantitative indicators, but also the qualitative indicators may be necessary. Thus Japan should also introduce the qualitative indicators into the performance plan/achievement degree report evaluation system for the evaluation of the communication field, etc.

\section{Hints to Chinese Action Program for Smooth Traffic and Transport from Japanese evaluation system}

Comparing the Chinese evaluation system of the action program for smooth traffic and transport with the Japanese evaluation system of the performance plan /achievement degree report (the local edition), the followings points may be considered to be applied for the improvement of the Chinese evaluation system.

\subsection{Relative evaluation for improvement}

An absolute evaluation to denote the improvement or deployment level is surely important. However, only absolute evaluation like what the Chinese evaluation requests may cause the cities in a really very low starting point to give up. Doing as what can be seen in the Japanese evaluation system, a relative evaluation by using the indicators such as a change rate comparing the year before can close up the effort of the organization and the officers.

\subsection{Introducing indicators on environmental issues}

Considering the importance of the environment, the indicators on both global and living environment issue such as noise and $\mathrm{CO}_{2}$ is should be performed.

\subsection{Allowing to take into consideration of local and special issues}

The uniformed indicators may limit the people to solve their local and special, but very important problems. Like that done by Mie Prefecture in Japan where the indicators relevant to sightseeing is incorporated in the tourist resort region, the evaluation system should allow the cities to make the consideration of their 
own necessities and incorporate unique indicators aiming at exploring and treating the local and special issues.

\subsection{Clarifying evaluation into the budget to complete PDCA cycle}

That the good evaluation as a "check" brings a rich budget for "action" can let us complete the PDCA cycle. Regarding this issue, to make the system management sustainable, the budget of the year after the evaluation should be linked, partly at least.

\subsection{Making evaluation open to public in detail actively and clearly}

Although the grade is opened to the public, what has been problem is not easily known over all cities. In Japan, the performance plan / achievement degree report of a local edition is specified by the Road Bureau, the Ministry of Land, Infrastructure and Transport, and it is easy to carry out comparison. Moreover, it is thought that the viewpoint of the outcome indicators will also be necessity from now on.

\section{Conclusion}

In this paper, the outline of the Chinese action program for smooth traffic and transport was reviewed by the implementation situation and the item of the evaluation indicators, and then the feature was clarified. To make a comparison, the Japanese performance plan / achievement degree report of local edition were summarized.

We think that the Chinese action program for smooth traffic and transport is functioning to raise the total level especially in developing countries. The good grade evaluation makes the cities proud of their achievements. The lower grade cities can clearly understand their next goal, the upper grade and finally the first grade.

On the other hand, the Japanese performance plan / achievement degree report of local edition system is much better to be applied for the developed countries. It is a road administration management system even incorporating budget allotment by achievements.

Both Chinese and Japanese evaluation systems may be improved by using hints from the other system. As the researchers know about both ones, we hope this paper will aid in the improvement of each evaluation system and, further extended, to be references for all developing and developed countries in the world in order to realize a sustainable development.

\section{Acknowledgements}

We were supported by Yaitai Traffic Police and Prof. Huapu LU at Tsinghua Univ. during this study. We wish to express our gratitude here. 


\section{References}

[1] Ando, R., On the evaluation indicators and system for urban road traffic in China (in Japanese), Proceedings of the Annual Conference of Chubu Branch of JSCE (Japan Society of Civil Engineers), pp. 349-350, 2008.

[2] Kawai, M. \& Ando, R., An urban transportation rating system and index in China (in Japanese), Proceedings of Infrastructure Planning, Vol. 38, CDROM Version, pp. 1-4, 2008.

[3] Ministry of Land, Infrastructure and Transport of Japan, The 2003-2007 Performance Plan / Achievement Degree Report, www.mlit.go.jp/road/ir/irperform/ir-perform.html.

[4] Ministry of Housing and Urban-Rural Development of the People's Republic of China, www.cin.gov.cn. 